\section{Chitosan Salt Gels Thermally Reversible Gelation of Chitosan}

Ryuji Yamaguchi, Shigehiro Hirano,* Yuji Arai and Tatsuro ITo

\begin{abstract}
Laboratory of Metabolic Chemistry, Institute of Applied Biochemistry, The University of Tsukuba, Sakura-mura, Niihari-gun, Ibaraki 300-3I

* Department of Agricultural Biochemistry, Tottori University, Tottori 680
\end{abstract}

Received June 19, 1978

Recently we reported the gelation of chitosan [(1 $\rightarrow 4)$-2-amino-2-deoxy- $\beta$-D-glucan] by $\mathrm{N}$ acylation with a series of carboxylic anhydrides $^{1,2)}$ and by the Schiff base formation with a series of aldehydes ${ }^{3}$ in aqueous acetic acid or in aqueous acetic acid-methanol solutions. The gels formed were not melted by heating and distinguishable from agarose and carrageenan gels, which exhibit the sol-gel-sol transformation on cooling and heating. ${ }^{4}$.

We now report that chitosan, which is dissolved in aqueous oxalic acid solutions by heating in a boiling water bath, forms novel gels of chitosan salt on cooling at room temperature. The gels melt on heating and set on cooling. This is the first report on the thermally reversible gelation of basic glycosaminans.

As shown in Table $I$, chitosan $\left\{[\alpha]_{D}^{28}-15^{\circ}\right.$ ( $c=1.0,10 \%$ acetic acid), the degree of $\mathrm{N}$ deacetylation $=0.85 /$ hexosaminyl residue $\}$ was dissolved in aqueous oxalic acid solutions at various concentrations in test tubes $(\phi=1.5 \mathrm{~cm})$ by heating on a boiling water bath. The bath was cooled to $5^{\circ} \mathrm{C}$ at a rate of $c a .0 .4^{\circ} \mathrm{C} / \mathrm{min}$, and gel-forming temperature was determined. The gel-forming temperature was defined as the lowest temperature at which the gelling solution did not flow down by inclining the test tube horizontally. The gel-forming temperature rose with increasing the concentrations of both oxalic acid and chitosan (Table I). The chitosan hydrooxalate gels were turbid and
Table I. Gel-forming Temperatures in Relation to THE Concentrations of Chitosan AND Oxalic Acid ${ }^{a}$

\begin{tabular}{|c|c|c|c|c|}
\hline \multicolumn{2}{|c|}{ Chitosan } & \multirow{2}{*}{$\begin{array}{l}\text { Oxalic } \\
\text { acid } \\
\text { (M) }\end{array}$} & \multicolumn{2}{|c|}{$\begin{array}{l}\text { Gel-forming } \\
\text { temperature }\end{array}$} \\
\hline \multicolumn{2}{|c|}{ Concentration } & & Gelation $^{b}$ & $\left( \pm 1^{\circ} \mathrm{C}\right)$ \\
\hline \multirow{3}{*}{0.5} & \multirow{3}{*}{25} & 0.25 & - & \\
\hline & & 0.50 & - & \\
\hline & & 1.00 & \pm & n.d. \\
\hline \multirow{3}{*}{1.0} & \multirow{3}{*}{50} & 0.25 & $+c$ & n.d. \\
\hline & & 0.50 & $+o$ & n.d. \\
\hline & & 1.00 & $t^{d}$ & n.d. \\
\hline \multirow{3}{*}{2.0} & \multirow{3}{*}{100} & 0.25 & $t^{d}$ & n.d. \\
\hline & & 0.50 & $\frac{1}{1} d$ & n.d. \\
\hline & & 1.00 & + & 9 \\
\hline \multirow{3}{*}{3.0} & \multirow{3}{*}{150} & 0.25 & + & 22 \\
\hline & & 0.50 & + & 30 \\
\hline & & 1.00 & + & 44 \\
\hline \multirow{3}{*}{4.0} & \multirow{3}{*}{200} & 0.25 & + & 30 \\
\hline & & 0.50 & + & 39 \\
\hline & & 1.00 & + & 52 \\
\hline \multirow{3}{*}{5.0} & \multirow{3}{*}{250} & 0.25 & + & n.d. \\
\hline & & 0.50 & + & 46 \\
\hline & & 1.00 & + & 58 \\
\hline
\end{tabular}

a The examination was performed in aqueous oxalic acid solutions $(5.0 \mathrm{ml})$. n.d., not determined. See the text for the experimental detail.

$b+$, gel was formed; - , no gel was formed.

$c$ Gelation occured after standing at $5^{\circ} \mathrm{C}$ for more than one week.

d Gelation occured after standing at $5^{\circ} \mathrm{C}$ overnight.

rigid, and they did not synerized. The melting temperatures were $\mathrm{ca} .80^{\circ} \mathrm{C}$ and $\mathrm{ca} .84^{\circ} \mathrm{C}$ for the gels formed from chitosan $(2.0 \%)$ and $0.25 \mathrm{M}$ and $1.0 \mathrm{M}$ oxalic acid solutions, respectively. The gels formed at more than $3.0 \%$ concentration of chitosan melted on heating for $5 \sim$ $10 \mathrm{~min}$ in a boiling water bath to give clear solutions. The solutions gelled again on cooling. The gels were stable in each of water, $0.5 \mathrm{M}$ acetate buffer $(\mathrm{pH} 4.5)$ and $5 \%$ acetic acid solutions at room temperature for several weeks.

Chitosan hydrooxalate gels were prepared from $3 \%$ chitosan $(150 \mathrm{mg}$ ) and $0.5 \mathrm{~m}$ oxalic acid $(5.0 \mathrm{ml})$. The gels were crashed to small pieces, and suspended in distilled water ( $\mathrm{ca}$. $25 \mathrm{ml}$ ). The suspension was packed into a column $(\phi=1.0 \mathrm{~cm})$, and the column was eluted with distilled water (ca. $200 \mathrm{ml}$ ) until the eluate was free of oxalic acid as examined 
by the redox titration with $0.01 \mathrm{M} \mathrm{KMnO}_{4}$. The gel was dehydrated by soaking in acetone $(200 \mathrm{ml})$ at room temperature for three days. The precipitates were collected by centrifugation, washed with ether and dried over $\mathrm{P}_{2} \mathrm{O}_{5}$ in vacuo at $100^{\circ} \mathrm{C}$ for $5 \mathrm{hr}$ to afford an amorphous product (151 mg). Found; C, 40.38; $\mathrm{H}, 6.08 ; \mathrm{N}, 5.98 \%$. Calcd. for $\left[\mathrm{C}_{6} \mathrm{H}_{10} \mathrm{NO}_{4}\right.$ $\left.(\mathrm{H})_{0.85}\left(\mathrm{COCH}_{3}\right)_{0.15} \cdot 0.45 \mathrm{C}_{2} \mathrm{H}_{2} \mathrm{O}_{4} \cdot 0.40 \mathrm{H}_{2} \mathrm{O}\right]_{n}: \mathrm{C}$, $40.19 ; \mathrm{H}, 6.09 ; \mathrm{N}, 6.51 \% . \quad$ IR $\nu_{\max }^{\mathrm{rBr}} 3450 \sim 3250$ $(\mathrm{OH}, \mathrm{NH}), 3000 \sim 2800,1680 \sim 1540\left(\mathrm{COO}^{-}\right.$ $\left.\mathrm{NH}_{3}{ }^{+}\right), 1150 \sim 1000 \mathrm{~cm}^{-1}(\mathrm{C}-\mathrm{O})$.

It was noteworthy that the water-washed gel melted on heating in a boiling water bath, but no gel was reformed on cooling to room temperature and afford suspension of chitosan hydrooxalate. The suspension gave clear solution on heating in a boiling water bath and turbid again on cooling to room temperature.

The gels were treated with alkali $(0.2 \%$ $\left.\mathrm{NH}_{4} \mathrm{OH}\right)$ after washing with water $(200 \mathrm{ml})$ to generate quantitatively chitosan and oxalic acid, which were determined by the isolation or the redox titration with $0.01 \mathrm{M} \mathrm{KMnO}_{4}$. The redox titration indicated the presence of 0.43 mole of oxalic acid/hexosaminyl residue in chitosan hydrooxalate gels and this value agreed closely with 0.45 mole of oxalic acid/ hexosaminyl residue as estimated from the elemental analysis.

Chitosan hydrosulfate gels which were fromed from the sulfuric acid solutions of chitosan exhibited essentially similar properties to those of the chitosan hydrooxalate gels on heating and cooling, but the gels were very brittle and collapsed by vigorous shaking of the containers.

These results indicate that 0.5 mole of oxalic acid or sulfuric acid/hexosaminyl residue is essential to retain the gel structure in water, and more excess of the acids are required to form the architecture of chitosan salt gels. Two acidic groups of these acid molecules form ammonium salts with amino groups of hexosaminyl residues of same or different chitosan chains, and chitosan chains are closslinked with acid molecules. The salts dissociate in solution on heating. The frame works may be similar to those of alginate and low methoxyl pectin gels which are formed with divalent cations $\left(\mathrm{Ca}^{2+}\right.$ etc. $)$ and uronic acid residues of polyuronide chains by salt formation..$^{5,6)}$ No gels were produced under the present conditions with other di- and polybasic acids such as phosphoric, boric, maleic, succinic, malic and citric acids.

A more detailed account of the structural study will be reported elsewhere.

\section{REFERENCES}

1) S. Hirano and R. Yamaguchi, Biopolymers, 15, 1685 (1976).

2) S. Hirano, Y. Ohe and H. Ono, Carbohydr. Res, 47, 315 (1976).

3) S. Hirano, R. Yamaguchi, N. Matsuda, O. Miuta and Y. Kondo, Agric. Biol. Chem., 41, 1547 (1977).

4) D. A. Rees, I. W. Steele and F. B. Williamson, J. Polymer Sci., Part C, 28, 261 (1969).

5) D. A. Rees, Chem. Ind. (London), 1972, 630.

6) R. Kohn, I. Furda, A. Haug and O. Smidsr $\dot{\text { d, }}$ Acta Chem. Scand., 22, 3098 (1968). 